\title{
Desenvolvimento rural sustentável por meio da licenciatura em Ciências Agrícolas
}

\author{
Sustainable rural development through licensing in Agricultural Sciences \\ Ramofly Bicalho \\ Suêda Caliari
}

Resumo: Este texto é parte da Dissertação de Mestrado intitulada "Licenciatura em Ciências Agrícolas, para além dos muros da escola: conhecimento e conexões rumo ao desenvolvimento rural sustentável". O objetivo do artigo é apresentar o contexto histórico de criação do curso de Licenciatura em Ciências Agrícolas (LICA) do Instituto Federal do Espírito Santo, Campus Itapina, analisando suas possíveis contribuições para o desenvolvimento rural sustentável no município de Colatina por meio de ações educacionais, via projetos de ensino, de pesquisa e de extensão. Utilizamos a abordagem qualitativa ao realizarmos análises bibliográfica e documental e uma roda de conversa que se baseou na metodologia da história oral focada em temas geradores. Entre as fontes de investigação, utilizamos também legislações, portarias, decretos e referenciais teóricos sobre a Licenciatura em Ciências Agrícolas e a educação do campo nos movimentos sociais. Apoiamo-nos numa perspectiva sociológica de investigação e de explicação dos processos sociais de participação dos sujeitos camponeses enquanto seres históricos e culturais. Inicialmente, apresentamos o contexto histórico de criação da LICA, Campus Itapina, bem como os projetos de ensino, de pesquisa e de extensão implantados na LICA. Por fim, expomos uma análise da importância do curso para o desenvolvimento rural sustentável em diálogo com a educação do campo e a agricultura familiar. Os resultados da pesquisa revelaram que o profissional licenciado em Ciências Agrícolas pode exercer mudanças diretas e indiretas que atendem à expectativa de melhoria da qualidade de vida dos produtores rurais e da sociedade. No entanto, para que isso aconteça, é preciso fomentar ainda mais os projetos de pesquisa, de ensino e de extensão no âmbito da formação profissional, juntamente aos sujeitos do campo.

Palavras-Chaves: Licenciatura em Ciências Agrícola; Políticas Públicas; Projetos de Ensino, de Pesquisa e de Extensão; Desenvolvimento Rural Sustentável.

Abstract: This text is part of the Master's Dissertation entitled "Licenciatura em Ciências Agrícolas, além os paredes da escola: conhecimento e conexões rumo ao desenvolvimento rural sustentável". The objective of the article is to present the historical context of the creation of the Degree in Agricultural Sciences (LICA) of the Federal Institute of Espirito Santo, Campus Itapina, analyzing its possible contributions to sustainable rural development in the city of Colatina through educational actions, via teaching, research and extension projects. We used the qualitative approach when carrying out bibliographic and documental analyses and a conversation in group based on the methodology of oral history focused on generating themes. Among the sources of research, we also use legislation, ordinances, decrees and theoretical references on the Degree in Agricultural Sciences and field education in social movements. We rely on a sociological perspective of investigation and explanation of the social processes of participation of peasant subjects as historical and cultural beings. Initially, we present the historical context of the creation of LICA, Campus Itapina, as well as the teaching, research and extension projects implemented at LICA. Finally, we present an analysis of the importance of the course for sustainable rural development in dialogue with rural education and family agriculture. The results of the research revealed that the graduate in Agricultural Sciences can make direct and indirect changes that meet the expectations 
of improving the quality of life of rural producers and society. However, for this to happen, research, teaching and extension projects in the field of professional training, together with the subjects of the field, must be further promoted.

Keywords: Degree in Agricultural Sciences; Public Policies; Teaching, Research and Extension Projects; Sustainable Rural Development.

\section{Introdução}

O presente artigo é fruto das pesquisas realizadas no curso de Licenciatura em Ciências Agrícolas (LICA) do Instituto Federal do Espirito Santo (IFES), Campus Itapina. Numa perspectiva histórica e emancipadora, este estudo foi desenvolvido no Programa de Pós-Graduação em Educação Agrícola (PPGEA) da Universidade Federal Rural do Rio de Janeiro (UFRRJ). Nosso objetivo principal foi compreender o processo de construção das experiências históricas de criação do curso, analisando sua contribuição para o Desenvolvimento Rural Sustentável do município de Colatina por meio das ações educacionais via projetos de ensino, de pesquisa e de extensão. Importante sinalizar que o referido município está localizado numa região voltada, predominantemente, para agricultura familiar. As questões abordadas caminham em direção à educação do campo, reconhecendo a importância das escolas no diálogo constante com os agricultores familiares e com suas comunidades.

Durante a pesquisa, foi desenvolvida uma roda de conversa com os representantes do Conselho de Desenvolvimento Rural Sustentável do município de Colatina. Essa conversa se baseou na metodologia da história oral, focada em temas geradores. A partir de um tema dado, geram-se perguntas e, consequentemente, novos temas e mais perguntas. "A técnica da dinâmica em si consiste em entrevistas devidamente guiadas pelo historiador" (CORREAA, 1978, p.13).

A pesquisa documental foi desenvolvida, predominantemente, em acervos bibliográficos com os educadores e estudantes da LICA, no IFES. Entre as fontes de investigação, utilizamos legislações, portarias, decretos e referenciais teóricos sobre o histórico de constituição das Licenciaturas em Ciências Agrícolas. Apoiamo-nos numa perspectiva sociológica de investigação e explicação dos processos sociais de participação dos sujeitos camponeses enquanto seres históricos e culturais. 
Desde o seu nascimento como Escola de Iniciação Agrícola até os dias atuais, o Instituto Federal do Espirito Santo, Campus Itapina, atua como importante instrumento de implementação do ensino agrícola no município de Colatina e demais regiões do entorno. Colatina possui um número considerável de pequenas e médias propriedades rurais que vivem, basicamente, da agricultura familiar.

Com a chegada dos Institutos Federais, atribui-se à Educação Profissional a função de articulação no desenvolvimento da região. Durante grande parte da sua história e com sua "vocação agrícola", o Campus Itapina executou inúmeras políticas de educação básica e profissional no município de Colatina. Sendo assim, este campus possui papel fundamental na formação técnica e cientifica dos jovens estudantes filhos de produtores rurais da região. Tais políticas colaboram para o desenvolvimento rural sustentável e a formação crítica dos sujeitos, individuais e coletivos, que atuam no Campo Capixaba.

Freire (2001) ressalta a importância da escola no processo de educação emancipatória para a formação crítica e, principalmente, o respeito às ideologias de cada grupo, pois é na escola que se têm a oportunidade de ler e de conhecer o que cada grupo pensa, acredita e propaga. Por isso, acreditamos que as ações de ensino, de pesquisa e de extensão implementadas pela Licenciatura em Ciências Agrícolas, em consonância com as demandas da região, podem minimizar essas divisões de classes bem como os problemas apresentados pelos agricultores familiares, frente às necessidades econômicas e sociais da região de Colatina. Além disso, estes projetos podem contribuir para o desenvolvimento rural sustentável a partir de processos educativos que valorizem as histórias de vida, as identidades e as memórias dos sujeitos, individuais e coletivos, do campo.

Trajetória histórica de criação do Curso de Licenciatura em Ciências Agrícolas - Campus Itapina

O curso de Licenciatura em Ciências Agrícolas do IFES, Campus Itapina, popularmente conhecido como LICA, é uma graduação autorizada pela resolução $n^{\circ}$ 14/2010 de 09/06/2010 (BRASIL, 2010). A primeira turma foi 
formada no segundo semestre desse mesmo ano e um dos fatores principais que contribuíram para a institucionalização foi a necessidade de ampliação dos cursos e a expansão da oferta de vagas exigidas por lei com a criação dos Institutos Federais.

A intenção do IFES, Campus Itapina, na oferta de cursos superiores era antiga. Há anos existia a solicitação da comunidade atendida, principalmente pelos egressos dos cursos técnicos, da oferta de cursos superiores pela instituição. Com o advento da Lei No 11.892/ 2008 (BRASIL, 2008) que cria os Institutos Federais, essa demanda ficou mais próxima de ser atendida. De acordo com a lei, os Institutos deveriam ofertar cursos técnicos, além de engenharias e licenciaturas.

Nesse contexto, inicia-se um enorme processo de expansão, incluindo a liberação de vagas para contratação de docentes e técnicos para atuarem, efetivamente, nos cursos superiores criados. Nas comissões, são analisadas as legislações, o mercado, a expectativa da população atendida pelo campus, as condições de infraestrutura e os recursos humanos. Em função de a Instituição possuir infraestrutura e quadro docente específico para a formação agropecuária e pedagógica, decidiu-se pela oferta de dois cursos superiores: Engenharia Agronômica e Licenciatura em Ciências Agrícolas. Um dos fatores decisivos na definição desses cursos foi a identidade do campus, a infraestrutura e a qualificação do corpo docente. Além disso, a decisão foi corroborada pelo artigo $6^{\circ}$, incisos III e IV da LEI 11.892, de 29/12/2008.

Art. $6^{\circ}$ : Os Institutos Federais têm por finalidades e
características: [...] III - promover a integração e a verticalização
da educação básica à educação profissional e educação
superior, otimizando a infraestrutura física, os quadros de
pessoal e os recursos de gestão; IV - orientar sua oferta
formativa em benefício da consolidação e fortalecimento dos
arranjos produtivos, sociais e culturais locais, identificados com
base no mapeamento das potencialidades de desenvolvimento
socioeconômico e cultural no âmbito de atuação do Instituto
Federal (BRASIL, 2008).

Sob a ótica da otimização de recursos, o inciso III propõe a integração curricular da educação básica com a profissional nos termos do Decreto $\mathrm{n}^{\circ}$ 5.154/2004 (BRASIL, 2004), assim como a oferta de cursos de educação básica 
e superior (art. 21, da Lei $n^{\circ}$ 9.394/96) (BRASIL, 1996) no mesmo projeto pedagógico. A opção por Engenharia Agronômica e Licenciatura em Ciências Agrícolas deu-se também em função do art. $7^{\circ}$, inciso IV, da LEI 11.892, de 29/12/2008.

Art. $7^{\circ}$ : Observadas as finalidades e características definidas no art. $6^{\circ}$ desta Lei, são objetivos dos Institutos Federais: [...] VI ministrar em nível de educação superior: a) cursos superiores de tecnologia visando à formação de profissionais para os diferentes setores; b) cursos de licenciatura, bem como programas especiais de formação pedagógica, com vistas na formação de professores para a educação básica, sobretudo nas áreas de ciências e matemática, e para a educação profissional; c) cursos de bacharelado e engenharia, visando à formação de profissionais para os diferentes setores da economia e áreas do conhecimento (BRASIL, 2008).

Na referida legislação, observamos que $50 \%$ das vagas anuais devem ser destinadas a cursos técnicos e um mínimo de $20 \%$ aos cursos de licenciaturas. Além da legislação apresentada, reiteramos como fatores preponderantes: 1) a localização da Instituição; 2) o público atendido, constituído, em sua grande maioria, por filhos de produtores rurais e meeiros; 3) a identidade da Instituição, com sua atuação histórica na oferta de cursos técnicos e de curta duração na área agrária, especialmente, agropecuária, zootecnia, agricultura e agroindústria.

A partir dessas análises, iniciou-se o processo de construção dos Projetos Pedagógicos dos Cursos (PPC) a serem ofertados. A construção do Projeto teve como referência duas Universidades Públicas que ofereciam a Licenciatura em Ciências Agrícolas: Universidade Federal Rural do Rio de Janeiro (UFRRJ) e Universidade Federal Rural de Pernambuco (UFRPE). Através dos estudos e do aprofundamento teórico acerca do Projeto Pedagógico dessas duas Universidades, o Campus Itapina elaborou toda estrutura do Projeto.

A minuta do Projeto Pedagógico do Curso seguiu os trâmites processuais e foi aprovada pela Resolução no 14/2010 do Conselho Superior do Instituto Federal do Espírito Santo, de 9 de junho de 2010. O curso teve sua primeira entrada anual no segundo semestre de 2010, ofertando 40 vagas em regime integral e diurno. Após a avaliação realizada pelo corpo docente e discente, além do Núcleo de Desenvolvimento e Ensino (NDE), uma primeira reestruturação do 
curso ocorreu, acarretando a redução de carga horária, a entrada anual no primeiro semestre letivo e o período noturno. O Curso de LICA possui conceito 04 (quatro) da Capes e conta com um total de 146 estudantes matriculados, segundo dados da secretaria escolar do IFES, ano de 2020.

O Campus Itapina viu na LICA possibilidades de contemplar sua realidade agrícola e de seus estudantes, colaborando na formação crítica e emancipadora de educadores e educadoras voltados a atender as demandas históricas, sociais e econômicas da região em diálogo com a realidade nacional.

A Licenciatura em Ciências Agrícolas é um curso consolidado, e criado no ano de 1963 pela Universidade Federal Rural do Rio de Janeiro. Ele foi, inclusive, o primeiro curso na América do Sul. Atualmente, são 21 cursos em todas as regiões brasileiras, especialmente, Norte e Nordeste do País (MORAES, 2014). A maioria dos cursos de licenciatura apresenta variações nas nomenclaturas e na organização curricular como: Licenciatura em Ciências Agrícolas; Licenciatura em Ciências Agrárias; Licenciatura em Ciências Agrárias e do Ambiente e Licenciatura em Educação do Campo - Ciências Agrárias.

Segundo o Projeto Pedagógico do Curso (IFES, 2011), a Licenciatura em Ciências Agrícolas tem como finalidade formar educadores/as que lecionem as disciplinas da área de Ciências Agrárias, a fim de atenderem as demandas da Educação Básica e Profissional Técnica de Nível Médio. O perfil desses profissionais está alicerçado numa política pedagógica que contemple a diversidade das Ciências Agrárias no Brasil. Parte-se de uma visão crítica, ética e contextualizada da realidade, capaz de contribuir para a transformação social pautada nos princípios da educação inclusiva. Essa formação colabora com a oferta de oportunidades e com a realização das potencialidades teóricas, práticas e metodológicas, integrando ensino, pesquisa e extensão por meio do comprometimento com o desenvolvimento sustentável.

Diante do Projeto Pedagógico, podemos concluir que esse curso forma educadores preparados para lidar com a realidade do entorno, atuando nas escolas inseridas no meio rural. Consequentemente, estes educadores também se encontram preparados para atenderem as famílias vinculadas à agricultura familiar. O curso possibilita, ainda, que o profissional atue em outras atividades, 
sendo extremamente importante para o empoderamento das atividades extensionistas. Compreende-se que os professores extensionistas podem oferecer contribuições significativas à comunidade onde atuam, uma vez que são conscientes da necessidade de respeitar as histórias, os aspectos individuais, coletivos, culturais e hábitos locais dos sujeitos. Nesse sentido, a Licenciatura em Ciências Agrícolas contribui para uma formação crítica e emancipadora, além de possibilitar a inserção dos estudantes no mercado de trabalho com o Desenvolvimento Rural Sustentável.

\section{Ações Educacionais com Base no Tripé: Ensino, Pesquisa e Extensão}

As atividades de Ensino, Pesquisa e Extensão fazem parte do rol das mudanças e exigências estabelecidas nos Institutos Federais de Educação. Elas possuem finalidades e características com o objetivo de fomentar programas de ensino que elevem, consideravelmente, os saberes e fazeres populares, estimulando a pesquisa e a extensão, em diálogo, com as potencialidades dos arranjos produtivos locais. Nesse sentido, os Institutos Federais têm o compromisso de intervir nos territórios, identificando problemas, criando soluções técnicas e tecnológicas para o desenvolvimento sustentável por meio da inclusão social. Para Pacheco (2011):

\footnotetext{
É na compreensão dos aspectos essenciais dessa relação e na sedimentação do sentimento de pertencimento territorial que se torna possível subverter a submissão de identidades locais a uma global. Esse caminho passa necessariamente por uma educação que possibilite ao indivíduo o desenvolvimento de sua capacidade de gerar conhecimentos a partir de uma prática interativa com a realidade. (PACHECO, 2011, p. 21).
}

Durante muitos anos, o Campus Itapina funcionou como Escola Agrícola. As estratégias pedagógicas e administrativas implantadas eram voltadas, exclusivamente, à realidade dos cursos técnicos. Os estudantes, em sua grande maioria, eram filhos de produtores rurais e os currículos sempre direcionados à área técnica. A matriz curricular era organizada para atender, predominantemente, o ensino, uma das bases do tripé proposto atualmente.

Atualmente, este Campus está atravessando um momento de transição com a implantação da interdisciplinaridade e da verticalização, ou seja, os 
estudantes têm acesso a todas as etapas de aprendizagens, desde o Ensino Médio Técnico Profissionalizante à Pós-Graduação Stricto Sensu na mesma instituição. Rompe-se com a organização de uma matriz curricular uniforme, estruturando-a de forma ampla com a intenção de atender às exigências das ações educacionais formadas pelo tripé: Ensino, Pesquisa e Extensão.

Com a reestruturação do ambiente institucional no referido Campus, acredita-se que a Licenciatura em Ciências Agrícolas, ao longo dos seus dez anos de implantação, vem contribuindo para o estabelecimento de diálogos por meio de processos educativos dinâmicos entre educadores, educandos e comunidades. A LICA promove a integração do conhecimento teórico com as práticas pedagógicas inovadoras numa estreita articulação com o contexto socioeconômico da região. Inclusive, ela promove também o desenvolvimento local e regional na perspectiva da construção cidadã, uma das finalidades dos Institutos Federais. Segundo Pacheco (2011):

Para tanto, é necessário um diálogo vivo e próximo dessas
instituições com a realidade local e regional, buscando a
compreensão de seus aspectos essenciais, ou seja, do que
existe de universal nessa realidade. Há de se considerar que
local e universal não existem como antítese, não expressam
necessariamente oposição de ideias, um não existe em
detrimento do outro, mas por vezes se justapõem, permeiam-se,
complementam-se e separam-se. (PACHECO, 2011, p. 21).

Nesse contexto, Pacheco (2011, p. 22) afirma que "os Institutos Federais se revelam como espaços que privilegiam a aprendizagem, inovação e transferência de tecnologia capazes de mudar a vida de milhares de brasileiros". Partindo dessa ótica, o tripé das ações educativas, ensino, pesquisa e extensão, presente nos IFES, oportuniza a produção de tecnologias que busquem solucionar problemas locais e regionais, além de habilitar a atuação dos sujeitos, considerando as condições produtivas, sociais e culturais. Para Silva (2009):

O desenvolvimento de processos educativos que levem a geração de trabalho e renda em prol do desenvolvimento local consolida a construção de uma proposta de formação que conduza o educando a novas possibilidades de ampliação de suas capacidades educativas e cognitivas. (SILVA, 2009, p. 44). 
Assim, as parcerias entre as instituições de ensino e as comunidades no entorno das escolas do campo, tão discutidas, podem ser um caminho de consolidação do desenvolvimento rural sustentável. O desafio é dar continuidade aos processos educativos de valorização do desenvolvimento local e regional pautado em conhecimentos, em princípios e em valores que potencializem a ação humana na busca de caminhos mais promissores como, por exemplo, o empoderamento da agricultura orgânica e agroecológica familiar.

A pesquisa, o ensino e a extensão são fortes instrumentos de articulação e de constituição das políticas públicas enquanto espaços de intervenção na comunidade escolar, principalmente, se forem articulados com as forças sociais da região com vistas à possibilidade de construção de novos caminhos. É oportuno sinalizar que a prática de atividades de pesquisa e extensão faz parte das atribuições dos Institutos Federais, práticas, inclusive, recomendadas em alguns incisos do art. $6^{\circ}$ da Lei $n^{\circ} 11.892$ de 29/12/2008.

I-Ofertar educação profissional e tecnológica, em todos os seus níveis e modalidades, formando e qualificando cidadãos com vistas na atuação profissional nos diversos setores da economia, com ênfase no desenvolvimento socioeconômico local, regional e nacional;

II - Desenvolver a educação profissional e tecnológica como processo educativo e investigativo de geração e adaptação de soluções técnicas e tecnológicas às demandas sociais e peculiaridades regionais;

III - Promover a integração e a verticalização da educação básica à educação profissional e educação superior, otimizando a infraestrutura física, os quadros de pessoal e os recursos de gestão;

VII - Desenvolver programas de extensão e de divulgação científica e tecnológica;

VIII - Realizar e estimular a pesquisa aplicada, a produção cultural, o empreendedorismo, o cooperativismo e 0 desenvolvimento científico e tecnológico;

IX - Promover a produção, o desenvolvimento e a transferência de tecnologias sociais, notadamente as voltadas à preservação do meio ambiente. (BRASIL, 2008).

Nesse sentido, é importante que os Institutos Federais promovam o desenvolvimento local por meio de soluções educacionais que contemplem o 
ensino, a pesquisa e a extensão, permitindo, de maneira efetiva, o acesso gratuito e de qualidade à educação profissional em todas as regiões do Brasil. É através do estímulo à pesquisa e dos programas de extensão, em articulação com as forças sociais da região, que os Institutos Federais terão condições de elaborar ações voltadas para as demandas peculiares de cada território.

O desafio, no campo da pesquisa, é ir além da descoberta científica. Seu principal objetivo é se fazer presente no processo de formação dos educadores, dos educandos e da comunidade. É importante compreender, ainda, que os conhecimentos produzidos pela pesquisa devem ser disponibilizados em favor do desenvolvimento socioeconômico local, regional e nacional. Tal desenvolvimento, no seio da sociedade, pode ser essencial no trabalho de resgate da cidadania e da transformação social.

Como o principal objetivo no campo da pesquisa é se fazer presente em toda comunidade escolar, a seguir, apresentaremos alguns projetos de ensino, de pesquisa e de extensão desenvolvidos na Licenciatura em Ciências Agrícolas do Instituto Federal do Espírito Santo, Campus Itapina.

\section{Conhecendo os Projetos de Ensino, de Pesquisa e de Extensão na LICA / IFES, Campus Itapina.}

Etimologicamente, a palavra "projeto" vem do latim projectus que significa "plano, noção inicial e detalhada do que se pretende desenvolver". Ao se construir projetos de ensino, de pesquisa e de extensão, pretende-se planejar, predominantemente, os objetivos e resultados que poderão ser alcançados. Segundo Gadotti (1994),

Todo projeto supõe rupturas com o presente e promessas com o futuro. Projetar significa tentar quebrar um estado confortável para arriscar-se, atravessar um período de instabilidade e buscar uma nova estabilidade em função da promessa que cada projeto contém de estado melhor do que o presente. (GADOTTI, 1994, p. 38).

Nessa perspectiva, os projetos buscam direcionamentos, tornando-se ações explicitas quando executadas em conjunto e não se limitando aos muros da escola. Quando as ações são exercidas em conjunto e destinadas a toda comunidade escolar, podem oportunizar aos sujeitos, individuais e coletivos, 
uma formação cidadã que respeite e valorize o meio em que se estuda, trabalha e produza as condições materiais de existência. Segundo Saviani (1983, p. 93), "A dimensão política se cumpre na medida em que ela se realiza enquanto prática especificamente pedagógica".

Nessa conjuntura, mapeamos três projetos que dialogaram com as políticas públicas de educação do campo e com a agricultura familiar:

Projeto de ensino "Aprendizagem e Vivência Prática da Agroecologia via instalação de Sistema Agroflorestal”.

Projeto de pesquisa “Implantação de 'Brinquedotécnica' na Área das Ciências Naturais na Escola Família Agrícola de Marilândia (ES)”.

Projeto de extensão "Semana da Agricultura Familiar de Colatina".

O principal critério de escolha dos projetos foi a sua ligação diretamente com os sujeitos do campo. Os três projetos supracitados envolveram diretamente os estudantes da Licenciatura em Ciências Agrícolas do IFES, Campus Itapina, as escolas do campo de Colatina e os agricultores familiares da região. Nesse contexto, foi possível compreender os benefícios que esse tripé representa para toda comunidade local, mostrando como tais ações, intercaladas, são importantes no desenvolvimento rural sustentável do município.

Projeto de ensino: Aprendizagem e vivência prática da agroecologia via instalação de sistema agroflorestal

Este projeto está ligado à atividade de ensino. Ele foi aprovado pelo edital PROEN n 01/2017 e teve como coordenador o professor Leandro Glaydson da Rocha Pinho. A proposta inicial é produzir, concomitantemente, espécies arbóreas, lavouras e hortaliças. A partir da leitura do projeto de ensino, ficou explícito a preocupação com o desenvolvimento sustentável do projeto em decorrência das várias discussões levantadas nos fóruns sobre sustentabilidade e sistemas de produção ecológicos.

A proposta foi desenvolver, no Campus Itapina, uma área produtiva adaptada com tecnologias do sistema florestal. Essa mesma área foi aproveitada para aulas práticas das disciplinas oferecidas pela Licenciatura em Ciências 
Agrícolas. As práticas agrícolas foram aliadas aos estudos teóricos, validando para os estudantes a possibilidade de intensificar e de diversificar a produção agrícola em áreas produtivas ou em estágio de recuperação.

A importância desse projeto para os estudantes da LICA foi extremamente relevante. Os autores do projeto, o professor e os estudantes do curso de LICA e Agronomia, destacaram a necessidade de ampliar a produção de conhecimento sobre a instalação do sistema agroflorestal, valorizando os saberes da agroecologia em diálogo com a realidade e os saberes cotidianos das comunidades envolvidas. Nesse projeto, educadores e educandos, a partir de seus conhecimentos prévios, comprovaram na prática, através de estudos comparativos e pesquisas, as teorias que embasaram o projeto em questão.

\section{Projeto de Pesquisa: Implantação de "Brinquedotécnica" na Escola Família Agrícola de Marilândia (ES)}

Esse projeto de pesquisa originou-se a partir de uma monografia produzida por Taíse Légora, estudante da Licenciatura em Ciências Agrícolas, durante seu estágio supervisionado na Escola Família Agrícola de Marilândia. Esta unidade pertence à rede "Movimento de Educação Promocional do Espírito Santo" (MEPES).

A implantação de uma "Brinquedotécnica", associando teoria e prática por meio da ludicidade, teve como objetivo principal auxiliar o processo de ensino e aprendizagem na estreita relação com educadores e educandos. Com este projeto, foram criados materiais didáticos para realização de aulas nas quais foram utilizadas metodologias lúdicas. No desenvolvimento da "Brinquedotécnica", a autora contou com a ajuda dos estudantes na produção dos materiais utilizando itens recicláveis de baixo custo e de fácil aquisição. Foram confeccionadas maquetes de construções, contemplando a produção agrícola, o sistema de irrigação e a coleção de insetos.

Destacamos que o processo de implantação da "Brinquedotécnica" ocorreu em articulação com as atividades desenvolvidas junto à gestão da escola de maneira articulada e institucionalizada. Esse projeto de pesquisa, desenvolvido com docentes, discentes e com a comunidade escolar de 
Marilândia, contribuiu para aproximar os sujeitos, individuais e coletivos, em prol da educação emancipadora.

\section{Projeto de Extensão: Semana da Agricultura Familiar de Colatina}

O referido projeto de extensão possui uma considerável amplitude, pois envolve a participação de servidores e estudantes do Campus Itapina, além de vários órgãos e entidades do município de Colatina como; o Sindicato dos Trabalhadores Rurais, o Instituto Capixaba de Pesquisa (INCAPER), a Assistência Técnica e Extensão Rural, a Secretaria de Desenvolvimento Rural, as Associações de Produtores Rurais, entre outros atores sociais.

A proposta desse projeto é oferecer aos pequenos produtores e órgãos ligados ao meio rural formação crítica e emancipadora por meio de minicursos, palestras e oficinas com temas variados. As temáticas são selecionadas por meio da realização de pesquisas acerca das demandas apresentadas pelos sujeitos camponeses e, posteriormente, atendidas por instituições públicas e privadas de Colatina. A preocupação maior do projeto foi manter um diálogo constante entre os diversos atores, especialmente, os produtores da região na interface com o IFES do referido campus.

O impacto social desse projeto na formação e na atuação dos estudantes é extremamente relevante. Eles se tornam os protagonistas do evento desde a organização das palestras até a participação nos minicursos e demais atividades. Nesse sentido, reiteramos que o objetivo do projeto é produzir conhecimento crítico que incentive a produção alternativa de renda e, consequentemente, melhore a qualidade de vida dos agricultores familiares de Colatina e região.

\section{Educação do campo: rumo ao desenvolvimento rural sustentável}

Na relação entre educação e desenvolvimento, devemos considerar que o ato educativo desempenhado pelas escolas do campo, com suas funções sociais, tem por natureza realizar ações políticas e intencionais que serão utilizadas na formação de sujeitos críticos, capazes de influenciar a sociedade 
onde vivem como agentes de transformação e desenvolvimento. Para Borges (2001), a educação, em sua essência, deve possibilitar a socialização e contextualização do ser humano na sociedade. Segundo Romanelli (2001), o processo de desenvolvimento social e as necessidades econômicas estão diretamente ligados à oferta da educação.

Os processos educativos devem colaborar com a leitura crítica e problematizadora da realidade, estabelecendo relações humanas com a escola e com a comunidade no seu entorno. Os diferentes tipos de desenvolvimento se relacionam a determinados modelos de educação.

No caso do desenvolvimento rural sustentável, os aspectos educacionais correspondentes estão voltados à valorização das políticas públicas no campo, considerando uma série de fatores: os valores locais, as questões culturais, históricas e ambientais que contribuam para formação integral dos sujeitos, individuais e coletivos. Afinal, ensinar não é transferir conhecimento, mas criar possibilidades para sua produção ou a sua construção (FREIRE, 1996).

Podemos afirmar que a escola é o território das vivências e convivências de educadores, de educandos e da comunidade. A escola é um espaço de encontros, de trocas e de busca pela produção crítica e emancipadora do conhecimento. Nesse sentido, a educação que se faz nas escolas do campo deve estar relacionada com as histórias, memórias, identidades e realidade das pessoas. Nessa perspectiva, Lima, Pires e Botelho (2010) declaram que:

No Brasil há uma mobilização nacional e um movimento de resistência em defesa de uma escola social e culturalmente referenciada para o mundo da agricultura familiar. Já existem inúmeras experiências exitosas neste sentido. Nestas modalidades educativas, a escola utiliza-se de pedagogias baseadas na abordagem construtivista, etnometodológicas, ou seja, a aquisição do conhecimento acontece num processo de construção. A construção de saberes é uma tarefa complexa, porque requer uma visão multidisciplinar. (LIMA; PIRES; BOTELHO, 2010, p. 03).

É preciso não perder de vista os aspectos sociais e culturais, as questões identitárias, os costumes e o contexto de vida das pessoas nas comunidades. A escola do campo deve considerar todos esses aspectos, respeitando o que tradicionalmente é realizado. São os processos de ensino e aprendizagem que 
vão se ampliando a partir das práticas etnometodológicas voltadas para o contexto de vida e realidade.

$\mathrm{Na}$ medida do possível, a escola do campo deve romper com as adaptações e improvisos, valorizando as características, as necessidades e as especificidades dos sujeitos que vivem e atuam neste território. Lima, Pires e Botelho (2010) afirmam que, historicamente, os movimentos sociais vêm reivindicando um sistema educacional que seja compatível culturalmente com as demandas apresentadas pelos agricultores familiares, assentados e acampados da reforma agrária, indígenas e quilombolas.

Freire (2001) afirma que as diferenças interculturais existem e apresentam-se sob a forma de divisão de classes, raça e gênero. Essas diferenças formam grupos sociais que, dependendo do nível de compreensão de tais diferenças, podem contribuir para aumentar o processo de discriminação. 0 autor ressalta, ainda, a importância da escola no processo de entendimento e de respeito às ideologias, enfrentando a discriminação. Em diálogo com a diversidade dos sujeitos, a escola tem a oportunidade de conhecer as especificidades de cada grupo.

Na compreensão dos movimentos sociais, as escolas do campo, na luta pela ampliação da educação básica, sinalizam que a pedagogia da alternância pode ser uma enorme possibilidade de fixação das suas bases. Elas lutam por uma pedagogia diferenciada no que tange as questões de organização, os modos de vida das pessoas e suas ruralidades. A pedagogia da alternância, segundo Bicalho e Oliveira (2017), é reconhecida como referência curricular e metodológica:

Ela tem origem no anseio de agricultores familiares em suas comunidades e no intuito de garantir educação e formação profissional diretamente articulada às histórias de vida, familiar, comunitária, cultural, de sustentabilidade local, entre outros aspectos. Propõe gestões participativas e colegiadas, estabelecendo relações cotidianas e de responsabilidade coletiva entre escola e comunidade. A alternância se fortalece nas ações dos sujeitos envolvidos num projeto local-nacional, que na nossa ótica é de educação popular, marcadamente sintonizado com os objetivos de organização da cultura e do trabalho do campo, o que difere das políticas neoliberais que estão sintonizadas com uma educação impessoal, de metas e mercadológica. (BICALHO; OLIVEIRA, 2017, p. 3). 
Em diálogo com Bicalho e Oliveira (2017), poderíamos utilizar a nomenclatura "Alternâncias". Este termo pode se referir à pluralidade de valores humanos, socioambientais e afirmação de identidades diante de si e do mundo. Sendo assim, em diferentes ambientes, nos espaços camponeses e urbanos, os sujeitos, individuais e coletivos, vivem a pluralidade de ideias e possuem diferentes realidades históricas, políticas, econômicas, sociais e culturais.

É preciso sistematizar algumas ideias que colaborem com o desenvolvimento rural sustentável na perspectiva da educação do campo, focando, principalmente, os jovens agricultores. Acredita-se que a educação emancipadora pode contribuir como elo de fortalecimento e de construção de conhecimento em bases sustentáveis.

Como descreve Tavares de Lima e Carneiro (2006), a trajetória de vida dos agricultores e agricultoras é marcada por lutas permanentes em relação à melhoria das condições de vida e conquista da terra, uma vez que eles lutam arduamente por mudanças e vislumbram as possibilidades de implementação da diversidade de instâncias educativas. As escolas do campo, nessa conjuntura, são peças fundamentais na trajetória de defesa da educação pública como direito de todos e dever do Estado.

Compreendemos que as políticas públicas de educação do campo são mecanismos que colaboram na construção de propostas e de ações acerca do desenvolvimento rural sustentável. Por outro lado, ao se depararem com a ausência histórica das políticas de educação do campo, os movimentos sociais se articulam, especialmente, em lutas travadas por uma educação condizente com suas realidades.

\section{Agricultura familiar e desenvolvimento rural sustentável}

A agricultura familiar no Brasil desempenha um importante papel na economia uma vez que é a responsável por grande parte da produção de alimentos que abastecem os centros urbanos. Todavia, Abramovay (2007) reconhece que, apesar da agricultura familiar estar ligada à inserção no mercado, o estado é o principal responsável por sua manutenção e seu desenvolvimento, principalmente por meio da adoção de políticas sociais e de 
financiamento que garantem sua existência. Segundo o referido autor, "o reconhecimento do trabalho do agricultor, mais do que isso, sua moldagem e a determinação de suas modalidades de organização, dependem do estado" (ABRAMOVAY, 2007, p.79).

Abramovay (2007) afirma que, no Brasil, o setor da agricultura familiar somente conseguiu um destaque no cenário econômico depois de serem implementadas medidas de financiamento sustentadas pelo governo, como é o caso do Programa Nacional de Fortalecimento da Agricultura Familiar (PRONAF). O programa foi regulamentado em junho de 1996 pelo governo brasileiro que contava com a parceria dos governos municipais e estaduais, além da iniciativa privada. O PRONAF tem como proposta o apoio ao desenvolvimento rural, amparando-se na agricultura familiar como segmento gerador de emprego e renda, visando o aumento da capacidade de produção e melhorando, consequentemente, a renda dos agricultores familiares.

A partir dessa abordagem, podemos observar que o espaço rural vai deixando de ser um lugar tido como "atrasado" e mero produtor de alimentos para os centros urbanos modernos, passando a ter uma visão contemporânea que ganha força em todas as dimensões do desenvolvimento.

Uma conquista recente diante de um passado, não tão distante, em que a agricultura e o meio rural eram vistos como obstáculos internos do desenvolvimento ou setores apenas subordinados aos ditames da urbanização e da industrialização. O rural era associado ao atraso, à pobreza e de onde se precisaria sair para alcançar os direitos básicos da cidadania. Apenas o setor dominante da grande propriedade era visto como produtivo e legítimo público da política econômica. Aos poucos o país vai tirando da invisibilidade imposta vários setores sociais e descobrindo a diversidade da agricultura e do meio rural, suas potencialidades para uma ocupação mais equilibrada do território e das regiões e para a própria sustentabilidade e o dinamismo do desenvolvimento nacional (FRANÇA; SORIANO, 2010, p.223).

Partindo dessa premissa, França e Soriano (2010) situam a abordagem territorial dos programas de desenvolvimento rural como uma flexão fundamental nas políticas anteriores. Dentro dessa ótica, Wanderley (2011) analisa a contribuição da abordagem territorial em relação ao debate contemporâneo sobre o futuro da agricultura familiar e do mundo rural brasileiro, destacando os 
desafios que se impõem à efetivação de uma estratégia de desenvolvimento fundada na participação cidadã e no empoderamento dos agricultores e comunidades rurais.

A partir dessa abordagem, podemos inferir que, para alcançarmos um desenvolvimento local/rural, é de suma importância que o desenvolvimento sustentável esteja pautado nas discussões relativas à conservação da natureza e ao crescimento econômico. Nessa perspectiva, o conceito de desenvolvimento sustentável que se encontra no relatório do Brundtland ${ }^{1}$ é:

O desenvolvimento sustentável é aquele que atende as necessidades do presente sem comprometer a possibilidade de as gerações futuras atenderem as suas próprias necessidades. Ele contém dois conceitos chaves: o conceito de necessidades essências dos pobres do mundo, que devem receber a máxima prioridade; e a noção das limitações que o estágio da tecnologia e da organização social impõe ao meio ambiente, impedindo de atender às necessidades presentes e futuras. (Comissão Mundial sobre Meio Ambiente e Desenvolvimento, 1998, p.46).

Esse contexto nos remete a pensar que a escolha de um meio rural melhor está relacionada à necessidade de se construir uma agricultura mais sustentável e que promova uma relação de qualidade de vida e do bem-estar das pessoas que vivem dela. É importante destacar que as políticas públicas que geram renda têm importante papel na melhoria das condições sociais dos agricultores familiares. A organização dos agricultores, a educação básica e profissionalizante, bem como a descentralização de políticas públicas são os caminhos primordiais para o desenvolvimento sustentável.

\section{Agricultura familiar em Colatina: desafios e potencialidades}

\footnotetext{
1 O Relatório Brundtland foi elaborado pela Comissão Mundial sobre o Meio Ambiente e o Desenvolvimento e faz parte de uma série de iniciativas anteriores à Agenda 21 as quais reafirmam uma visão crítica do modelo de desenvolvimento adotado pelos países industrializados, reproduzido pelas nações em desenvolvimento e que ressaltam os riscos do uso excessivo dos recursos naturais sem considerar a capacidade de suporte dos ecossistemas. O relatório aponta para a incompatibilidade entre desenvolvimento sustentável e os padrões de produção e consumo vigentes. Em 1987, a divulgação do Relatório Brundtland, intitulado "Nosso futuro comum" pela Comissão Mundial sobre Meio Ambiente e Desenvolvimento das nações unidas (1988), popularizou a expressão "desenvolvimento sustentável" e sua definição foi considerada a mais próxima do consenso oficial (COMISSÃO MUNDIAL SOBRE MEIO AMBIENTE E DESENVOLVIMENTO, 1998).
} 
A estrutura fundiária de Colatina2 retrata o predomínio das pequenas propriedades de base familiar. Os trabalhos produtivos são feitos pela própria família ou no regime de parcerias agrícolas, oferecendo importante fonte de ocupação da força de trabalho. Podemos dizer que Colatina é um município composto, em sua maior parte, por propriedades de pequeno porte que utilizam, em grande medida, a mão de obra familiar. É nesse contexto, que a agricultura familiar colatinense ganha reconhecimento. Ela é estratégica e ocupa importante papel do ponto de vista socioeconômico, contribuindo para geração de renda no meio rural.

Colatina apresenta uma taxa de crescimento anual de 1,88\%. Todavia, no relatório INCAPER (2011), o percentual da população rural vem diminuindo em relação à população total, uma vez que passou de, aproximadamente, 19\% no Censo de 1990 para 14\% em 2008 e para 12\% no Censo de 2010. Atualmente, segundo o site da prefeitura, Colatina é uma cidade de 1.416 quilômetros quadrados, com 123 mil habitantes, sendo que $88 \%$ residem na área urbana e $12 \%$ na zona rural. Nessa conjuntura, é possível percebermos uma tendência ao êxodo rural devido ao aumento das diversas dificuldades acerca da agricultura familiar.

Segundo Caldart (2004), a agricultura moderna promovida pelo capitalismo, em meados do século passado, muito contribuiu para o aumento da desigualdade entre a agroindústria e a agricultura tradicional. Essas questões motivaram, significativamente, o êxodo rural e o atraso nas relações sociais presentes no contexto atual.

A maior atividade econômica agrícola de Colatina é conduzida pela produção de café conilon. Em segundo lugar, se encontra a pecuária principalmente na modalidade de corte. O município conta hoje com o Frigorífico Rio Doce (FRISA), um dos maiores do país e responsável pela grande parte da comercialização do gado de corte e do leite que são destinados às cooperativas e aos laticínios da região.

\footnotetext{
2 Disponível em http://www.colatina.es.gov.br/acidade/?pagina=geografia Acesso em 14 de dezembro de 2020.
} 
Outras culturas como a do arroz, do feijão, do cacau, da goiaba, do coco, da banana, do limão e da graviola também são desenvolvidas no município. Uma das maiores dificuldades dessas culturas é a exigência de espaços para armazenamento e o acesso rápido ao mercado, além da baixa produção e comercialização de tais produtos. A fruticultura, com a produção da manga, é outro ramo que vem ganhando destaque na economia agrícola de Colatina. Seu cultivo é incentivado em função das características climáticas favoráveis e das garantias de comercialização através da estruturação do polo de manga em Linhares.

O agroturismo em Colatina é outra potencialidade do município com destaque para a região de São Pedro Frio. Este território possui uma quantidade significativa de nascentes preservadas pelos agricultores familiares que construíram barragens em suas propriedades com equipamentos cedidos pela prefeitura. Existe, ainda, a oferta de linhas de crédito como, por exemplo, o Programa Nacional de Agricultura Familiar (PRONAF), utilizado por várias associações de produtores rurais, sindicatos e demais parceiros ligados à cadeia produtiva do município.

Por outro lado, fatores como a queda da fertilidade do solo, a distribuição irregular das chuvas, a diminuição do volume de água, o baixo nível de organização social dos produtores, a baixa qualidade, a produtividade e a comercialização das culturas, além da dependência em relação ao café e à pecuária, tem provocado o empobrecimento de grande parte das propriedades agrícolas, limitando a capacidade de investimento dos produtores e causando um efeito cíclico retroalimentado pelo atual contexto da agricultura colatinense, conforme dados do INCAPER (2011).

Tratamos de uma região que possui um número considerável de pequenas e médias propriedades rurais que, basicamente, vivem da agricultura familiar que necessita de acesso às políticas de educação, de cultura e de outros direitos sociais para que consigam transpor esses desafios. Um aporte extensionista, com projetos e propostas voltados para as demandas locais, são ações que podem cooperar para a solução desses empasses. 
$\mathrm{Na}$ interface com seus projetos de ensino, pesquisa e extensão, o Instituto Federal do Espírito Santo, Campus Itapina, tem trabalhado para buscar soluções de enfrentamento aos problemas mencionados. Acreditamos que a socialização das tecnologias e a abordagem do conhecimento participativo podem potencializar o desenvolvimento rural sustentável, além de promover a qualidade de vida dessas famílias em diálogo com suas histórias, memórias e identidades.

Durante grande parte da sua história, o Campus Itapina vem executando a política de educação profissional no município de Colatina, formando força de trabalho para atuar no setor agrícola. Acreditamos que o referido Campus e a LICA terão seus resultados potencializados, cumprindo, assim, sua missão social acerca do ensino agrícola quando políticas públicas de educação e pesquisas colaborarem na ampliação de novas tecnologias de irrigação, de colheita e de cultivo, fortalecendo os agricultores familiares e suas organizações como as associações de produtores rurais, os movimentos sociais e os sindicatos. No entanto, transpor essas barreiras por meio das ações de ensino, de pesquisa e de extensão no município de Colatina é desafiador para o curso de LICA no Campus Itapina.

\section{Considerações Finais}

A oferta da Licenciatura em Ciências Agrícolas (LICA) no Campus Itapina é essencial na formação dos educadores do campo. Com essa Licenciatura, muitos jovens agricultores, pela primeira vez, tiveram a oportunidade de realizar um curso superior em uma Instituição Pública de ensino. A LICA tem se tornado um importante aliado para os sujeitos do campo, individuais e coletivos, além de formar educadores preocupados com as especificidades camponesas. Essas questões podem potencializar o desenvolvimento sustentável da região, especialmente, a valorização da agricultura familiar e suas implicações sociais, políticas e econômicas.

O educador formado pela Licenciatura em Ciências Agrícolas pode exercer mudanças diretas e indiretas que atendem às expectativas de melhoria da qualidade de vida dos produtores rurais e da sociedade como um todo. Ele toma posse do ensino agrícola profissionalizante num estreito diálogo com a 
produção do conhecimento vinculada às ciências agrárias, ao meio ambiente, à sustentabilidade, à agricultura familiar agroecológica e orgânica, à agroindústria, entre outros.

Buscamos entender as ações que colaboraram com a melhoria da qualidade de vida dos sujeitos camponeses e compreender a realidade dos pequenos produtores por meio da valorização da ciência, do saber popular e da consciência ambiental. Certamente, essas articulações podem ser a chave para a promoção do desenvolvimento rural sustentável. A luta por políticas públicas de educação do campo articuladas às questões teóricas e práticas desenvolvidas nos projetos de ensino, de pesquisa e de extensão, voltados para as demandas locais, são ações que cooperam para o desenvolvimento sustentável do território rural de Colatina.

Por fim, evidenciamos que a oferta da Licenciatura em Ciências Agrícolas, no Campus Itapina, foi uma decisão bastante acertada. Ela oportunizou conhecimento científico e popular a um conjunto significativo de educadores e de educandos, além de alcançar a comunidade no entorno composta por sujeitos com inúmeras limitações de acesso ao mundo acadêmico e ao desenvolvimento de tecnologias. Novamente ressaltamos que, os projetos de ensino, de pesquisa e de extensão, em diálogo com as demandas locais, foram essenciais nos debates e na promoção do desenvolvimento rural sustentável. Tais projetos, certamente contribuíram para a transformação e o desenvolvimento econômico e social dos produtores rurais de Colatina, representantes legítimos da agricultura familiar brasileira.

\section{Referências Bibliográficas}

ABRAMOVAY, R. Agricultura familiar e assentamentos. Estudos prospectivos territoriais e temáticos referenciados no território. Subsídio à elaboração do PPA. São Paulo. 2007.

BICALHO, R.; OLIVEIRA, J. R.. Interfaces entre educação profissional e pedagogia da alternância. SÉRIE-ESTUDOS (UCDB), Campo Grande, MS, v. 22, n. 46, p. 195-212, set./dez, 2017.

BORGES, H. S. Construção do currículo da educação de jovens e adultos. In: Núcleo de Publicação (UFSC/CED). 2001. 
BRANDENBURG, A. Agricultura e Desenvolvimento Sustentável. In: AGUIAR, D. R. D.; BENEDITO, J. (Ed.). O agronegócio brasileiro: desafios e perspectivas. Sociedade brasileira de economia e Sociologia Rural. 102 p. 2 v. 1998.

BRASIL. Casa civil. Subchefia para assuntos jurídicos. Decreto n5.154 de 23 de julho de 2004. Disponível em http://www.planalto.gov.br/ccivil 03/ ato20042006/2004/decreto/d5154.htm Acesso em 2 abr.2019.

BRASIL. Casa civil. Subchefia para assuntos jurídicos. Lei $\mathbf{n}^{\circ} \mathbf{9 . 3 9 4}$, de dezembro de 1996. Disponível em http://www.planalto.gov.br/ccivil 03/leis/l9394.htm Acesso em 15 abr. 2019.

BRASIL. Casa civil. Subchefia para assuntos jurídicos. Lei $\mathbf{n} .11 .892$, de 29 de dezembro de 2008. Disponível em: http://www.planalto.gov.br/ccivil 03/ ato2007-2010/2008/lei/l11892.htm Acesso em: 25 jan. 2020.

BRASIL. Ministério da educação. Resolução do conselho superior n014/2010, de 9 de junho de 2010. Disponível em https://www.ifes.edu.br/images/stories/files/Institucional/conselho superior/2016 /Res CS 142010 - Alterada pela Res CS 282016 Licenciatura em Ciencias Agricolas - Itapina.pdf Acesso em: 3 set. 2019.

CALDART, R. S.. Sobre educação do campo. In: SANTOS, C. A.. (Org.). Por uma Educação do Campo: Políticas Públicas - Educação. Incra/MDA. p.67-86. Brasília, DF, 2008. Disponível em https://educanp.weebly.com/uploads/1/3/9/9/13997768/por uma educao do C ampo.pdf Acesso em 03 mar. 2019.

COMISSÃO MUNDIAL SOBRE O MEIO AMBIENTE E DESENVOLVIMENTO. (CMMAD). Nosso futuro comum. Rio de Janeiro: Fundação Getúlio Vargas, 1988.

CORREAA, C. H. P. História oral, teoria e técnica. Florianópolis: UFSC, 1978.

COSTA, F. A. CARVALHO, H. M. Agricultura Camponesa. In: Dicionário da Educação do Campo. CALDART, et. al. Rio de Janeiro, São Paulo Escola Politécnica de Saúde Joaquim Venâncio, Expressão Popular, 2012.

FREIRE, P. Pedagogia da Autonomia: saberes necessários à prática educativa. São Paulo: Paz e Terra, 1996.

FREIRE, P.. Política e Educação. Cortez. Coleção Questões da Nossa Época, v.23, 2001.

GADOTTI, M.. Pressupostos do projeto pedagógico. In: MAC, Anais da Conferência Nacional de Educação para Todos. 28/8 a 2/9. Brasília, 1994.

IFES. Instituto Federal de Educação, Ciência e Tecnologia do Espírito Santo. Projeto Pedagógico de Curso de Licenciatura em Ciências Agrícolas. Itapina. 
2011. Disponível em https://www.ifes.edu.br/cursos/graduacao/licenciatura-emciencias-agricolas Acesso em 05 de maio de 2019.

LIMA, I. S.; PIRES, A. H. B.; BOTELHO L. C.; A Educação do Campo para o Desenvolvimento Rural e a Formação de Agricultores. XXXIII Congresso Brasileiro de Ciências da Comunicação.2010, Disponível em: http://www.intercom.org.br/papers/nacionais/2010/resumos/R5-2433-1.pdf

Acesso em 28 abr. 2020.

MORAES, M. A.. A formação de licenciados em Ciências Agrícolas/Agrárias: o conhecimento e suas conexões. Educação v.39, n.3. set. /dez. Rio de Janeiro. 2014.

PACHECO, E. (Org.). Institutos Federais: Uma Revolução na Educação Profissional e Tecnológica. Brasília, São Paulo, 2011.

PROGRAMA DE ASSISTÊNCIA TÉCNICA E EXTENSÃO RURAL PROATER 2011 - 2013. PLANEJAMENTO E PROGRAMAÇÃO DE AÇÕES. INCAPER Instituto Capixaba de Pesquisa, Assistência Técnica e Extensão Rural. Disponível em: https://incaper.es.gov.br/media/incaper/proater/municipios/Noroeste/Colatina.pd f. Acesso em: 05 mar. 2020.

ROMANELLI, O. História da educação no Brasil. Vozes 25. ed. Petrópolis, 2001.

SAVIANI, D.. Para além da curvatura da vara. In: Revista Ande no 3. São Paulo, 1983.

SILVA, C. J. R. (org.). Institutos federais - Lei $n^{\circ} 11.892$, de 29/12/2008: comentários e reflexões. Natal: IFRN, 70 p. 2009.

TAVARES DE LIMA, J.; CARNEIRO, S. Q. Desenvolvendo o Local com Severinos e Quitérias. In TAVARES DE LIMA, J. R. (org.). Extensão Rural e Desenvolvimento Sustentável. Recife: Bagaço. 03. P. 71-92, 2006.

WANDERLEY, M. N. B.. Um saber necessário: os estudos rurais no Brasil. Campinas, SP: Ed. da Unicamp, 2011.

\section{Sobre os autores}

\section{Ramofly Bicalho}

ramofly@gmail.com

Professor Associado II na UFRRJ - Universidade Federal Rural do Rio de Janeiro, Campus Seropédica. Lotado no Departamento de Educação do Campo, Movimentos Sociais e Diversidade. Docente na Licenciatura em Educação do Campo, no PPGEA - Programa de Pós-Graduação em Educação Agrícola e no PPGEduc - Programa de Pós-Graduação em Educação, Contextos Contemporâneos e Demandas Populares. Pós-Doutorado em Educação na Universidade Federal Fluminense - UFF. Atua com as seguintes temáticas: 
História da Educação do Campo e Movimentos Sociais. Educação Popular e Educação de Jovens e Adultos.

\section{Suêda caliari}

scaliari@ifes.edu.br

Assistente em Administração no IFES - Instituto Federal do Espírito Santo, Campus Itapina. Mestrado em Educação Agrícola na UFRRJ - Universidade Federal Rural do Rio de Janeiro. PPGEA - Program de Pós-Graduação em Educação Agrícola. 